\title{
A Comprehensive Study of the Alteration of Ignitable Liquids by Weathering and Microbial Degradation
}

Dee A. Turner, Ph.D. ${ }^{1}$

Mary Williams, M.S. ${ }^{2}$

Michael A. Sigman, Ph.D. ${ }^{2}$

*John V. Goodpaster, Ph.D. ${ }^{1}$

${ }^{1}$ Department of Chemistry and Chemical Biology, Indiana University Purdue University Indianapolis (IUPUI), 402 North Blackford Street, LD 326, Indianapolis, IN 46202

${ }^{2}$ National Center for Forensic Science (NCFS), Department of Chemistry, University of Central Florida, Orlando, FL

* Corresponding Author

This work was funded by the National Institute of Justice, Office of Justice Programs, U.S. Department of Justice (Award No. 2011-DN-BX-K539). The opinions, findings, and conclusions or recommendations expressed in this publication are those of the authors and do not necessarily reflect those of the U.S. Department of Justice.

This is the author's manuscript of the article published in final edited form as:

Turner, D. A., Williams, M., Sigman, M. A., \& Goodpaster, J. V. (2017). A Comprehensive Study of the Alteration of Ignitable Liquids by Weathering and Microbial Degradation. Journal of Forensic Sciences. http://doi.org/10.1111/1556-4029.13527 


\begin{abstract}
The differing effects of weathering and microbial degradation are described here in a comprehensive study that involved 50 different ignitable liquids from the Ignitable Liquids Database and Reference Collection. Examples of ILRs from each of the main classes established by the American Society of Testing and Materials (ASTM) are presented. Weathering was accomplished via evaporation whereas microbial degradation was carried out on soil at room temperature for periods of up to 21 days. Major trends included the rapid degradation of long n-alkanes and monosubstituted alkyl benzenes (e.g., toluene, ethylbenzene, and propylbenzene). Surprisingly, some longer branched alkanes (e.g., trimethyloctanes) were also susceptible to microbial attack. Although all ignitable liquids examined suffered at least to some extent from microbial degradation, gasoline, petroleum distillates, and oxygenates were the most susceptible. Isoparaffinic and naphthenic paraffinic products were the most resistant to microbial degradation.
\end{abstract}

KEY WORDS: Forensic science, ignitable liquids, microbial degradation, weathering, soil, biodegradation 
The investigation of a suspicious fire relies upon a successful collaboration of criminal investigators, fire investigators, technical experts, and forensic chemists. One of the key findings in such an investigation is that debris gathered from the fire scene contains residues of an ignitable liquid. As most ignitable liquid residues (ILRs) originate from readily available petroleum products, it has been a long-standing practice to classify ILRs per their chemical composition and boiling point range [1].

However, the chaotic nature of a fire can confound this effort. This is manifested as low levels of residue, naturally present volatiles (e.g., terpenes), background contaminants (e.g., tar, asphalt) and pyrolysis products from polymeric substrates (e.g., rubber, plastic, carpet padding) $[2,3]$. The nature of the ILR itself can also be perturbed via two main processes. The first, weathering, describes the degradation of an ignitable liquid due to evaporation or partial burning. This results in a predictable loss of low boiling compounds relative to high boiling compounds. The second, microbial degradation, can occur in fire debris samples that contain soil, rotting vegetation or other substrates that may support large populations of bacteria. This results in preferential loss of readily metabolized compounds such as straight chain alkanes and mono-substituted aromatics [4]. Prior research into the forensic implications of microbial degradation began over 20 years ago with the seminal work of Mann and Kirkbride $[5,6]$. Since then, the effect of microbial degradation on a wide variety of ignitable liquids has been reported $[7,8]$. The extent to which degradation is reproducible and results in changes different than those seen in weathering has also been described for gasoline [9]. Abiotic factors such as soil type and season have also been studied $[10,11]$. Fortunately, preserving ILRs in fire debris evidence can be accomplished by either freezing evidence upon arrival to the laboratory or by adding chemical preservatives in the field [12].

For the results from a fire debris analysis to be successfully interpreted, a comprehensive database is needed that contains samples of all classes of ignitable liquids that 
have been subjected to both evaporation (weathering) and microbial degradation. To date, a direct comparison of weathering and degradation has been reported only for gasoline [9]. A database will be a valuable tool for fire debris analysts in the identification and classification of ignitable liquid residues.

The purpose of the work presented here was to observe any changes in an ignitable liquid due to weathering or microbial degradation. Multiple examples from each ASTM E161811 classification were obtained from the Ignitable Liquids Reference Collection (ILRC) at the University of Central Florida (http://ilrc.ucf.edu/). The resultant data were added to the ILRC database and related back to the original non-degraded ignitable liquid. The ILRC database was developed by the National Center for Forensic Science (NCFS) at the University of Central Florida and the Scientific Working Group for Fire and Explosions (SWGFEX) to aid forensic chemists in interpretation of the ILR in fire debris.

\section{Materials and Methods}

Materials

The ignitable liquids were obtained from the ILRC and are listed in Table 1. The substrate used was Hyponex ${ }^{\circledR}$ brand potting soil obtained from K-Mart. Activated charcoal strips were obtained from Albrayco Technologies. Quart-sized paint cans were obtained from Best Containers. Carbon disulfide was purchased from Fisher Scientific. 


\section{Weathering Experiments}

All weathering experiments were conducted at NCFS. The ignitable liquids were evaporated (weathered) by volume to remove approximately 25, 50, 75, 90 and 95 percent of the original volume. Weathering was performed in $10 \mathrm{~mL}$ conical vials with 0.1 graduations. The vial was filled to the $10 \mathrm{~mL}$ mark and evaporated to volume under a continuous stream of nitrogen to assist in evaporation. Heat was applied via a dry bath to aid in the evaporation of some ignitable liquids. A volume of 20 microliters $(0.02 \mathrm{~mL})$ was added to $1 \mathrm{~mL}$ of $\mathrm{CS}_{2}$ for $\mathrm{GC}$ MS analysis for all samples.

\section{Microbial Degradation Experiments}

All microbial degradation experiments were conducted at IUPUI. Each ignitable liquid $(20 \mu \mathrm{L})$ was spiked onto approximately $100 \mathrm{~g}$ of potting soil inside a quart-sized paint can. Four identical cans were prepared for each ignitable liquid. One can was immediately extracted as described below and the remaining three were sealed and aged. After storage at room temperature for 7,14 , and 21 days, the sealed cans were re-opened and a whole carbon strip was suspended on a paper clip into the headspace of the can. The can was then resealed and baked at $65^{\circ} \mathrm{C}$ for 16 hours. Upon cooling the can to room temperature, the carbon strip was removed and cut in half. One half of the strip was placed into a vial with $500 \mu \mathrm{L}$ of carbon disulfide for analysis.

\section{Instrumental Analysis}

Gas chromatography-mass spectrometry analysis was performed using an Agilent 6890 gas chromatograph and 5973 mass spectrometer utilizing an auto-sampler. One microliter of the diluted ignitable liquid was injected into a $250^{\circ} \mathrm{C}$ injection port. The compounds were separated by a $100 \%$ dimethylpolysiloxane (HP-1) capillary column with a film thickness of $0.50 \mu \mathrm{m}$, a nominal diameter of $200 \mu \mathrm{m}$, and $25 \mathrm{~m}$ length. Helium gas was maintained at a 
constant flow rate of $0.8 \mathrm{ml} / \mathrm{min}$ with an average linear velocity of $36 \mathrm{~cm} / \mathrm{sec}$. The injection was split in a 50:1 ratio. The initial oven temperature of $50^{\circ} \mathrm{C}$ was held for 3 minutes, followed by a temperature ramp of $10^{\circ} \mathrm{C} / \mathrm{min}$ to a final temperature of $280^{\circ} \mathrm{C}$, which was held for 4 minutes. The mass spectrometer transfer line temperature was $250^{\circ} \mathrm{C}$ with a source temperature of $230^{\circ} \mathrm{C}$ and a quadrupole temperature of $150^{\circ} \mathrm{C}$. Mass spectra were acquired between 30 and 350 mass to charge ratio at an acquisition rate of 2-3 scans/second. The detector was turned off between 1.54 and 2.00 minutes during solvent elution.

\section{Results and Discussion}

The effects of weathering and microbial degradation are distinct and can be separately observed in the chromatograms of the ignitable liquids presented here. In this work, several ignitable liquids in each ASTM class were weathered up to $95 \%(v / v)$ via evaporation under nitrogen. In addition, un-evaporated samples were subjected to microbial degradation on potting soil for up to 21 days. The results for one liquid from each ASTM class will be presented and discussed. The chromatograms for all other liquids listed in Table 1 can be found in the Ignitable Liquids Database and Reference Collection (ILRC).

Gasoline is the most common ignitable liquid encountered in casework. This liquid contains a significant contribution of aromatic compounds but also contains normal, branched and cyclic alkanes with a minor contribution of naphthalenes. The set of chromatograms on the left side of Figure 1 show the effects of weathering while the set of chromatograms on the right show the effects of microbial degradation. As can be seen in Figure 1, weathering of gasoline results in the loss of the branched alkanes that elute between 0 and 4 minutes. There is also nearly total loss of toluene $\left(t_{r}=4.9 \mathrm{~min}\right.$ ) and the $C_{2}$-alkylbenzenes (between $6.9-7.5$ min) once 
the liquid is highly (90\%) weathered. Conversely, weathering results in a relative increase in abundance of heavier components, beginning with the $C_{3}$-alkylbenzenes (between $8-10 \mathrm{~min}$ ).

In contrast, microbial degradation causes the selective loss of certain compounds based upon chemical structure, not boiling point. The compounds that are degraded most rapidly are the mono-substituted alkylbenzenes: toluene $\left(t_{r}=4.9 \mathrm{~min}\right)$, ethyl benzene $\left(t_{r}=6.9 \mathrm{~min}\right)$ and propyl benzene $\left(t_{r}=8.9 \mathrm{~min}\right)$. After 7 days, the loss of ethyl- and propyl benzene clearly perturb the peak height ratios of the $\mathrm{C}_{2}$ - and $\mathrm{C}_{3}$-alkylbenzenes. The biodegradation of SRN 116 also demonstrates these changes, as found in the ILRC.

For most gasolines, samples aged between 7 and 21 days were degraded to the point where the alkylbenzenes could not positively be identified by their mass spectra. By 21 days, the peaks for all alkyl benzenes essentially disappeared from the chromatogram. Note that the $\mathrm{C}_{3}$-alkylbenzenes must be present in a fire debris sample to classify an ignitable liquid residue as gasoline according the ASTM E1618-11. In addition, the peak height ratios of these compounds must be consistent with that of a gasoline standard.

Figure 2 compares the effects of weathering and microbial degradation in a heavy petroleum distillate (HPD). Weathering of an HPD results in the systematic loss of low boiling compounds regardless of chemical structure (i.e., alkyl benzenes, branched alkanes and nalkanes). As the extent of weathering increases, more and more of the higher boiling compounds are lost, increasing the relative intensity of the less volatile compounds left behind. The result of this phenomenon is a clear difference between the range of retention times observed in a pristine HPD (9.5 - $22.5 \mathrm{~min})$ and the range of retention times seen in a $90 \%$ weathered sample $(20.7-27.2 \mathrm{~min})$.

Before discussing the biodegradation of HPD, there is an important abiotic factor to consider. These ILRs contain a significant amount of high boiling n-alkanes (e.g., n- $\mathrm{C}_{19}$ and 
up), however, the recovery of these compounds from a soil substrate is relatively poor. A comparison of the unevaporated HPD to that of an HPD recovered from soil at 0 days illustrates this point in that $n$-alkanes as large as $n-C_{23}$ are readily identified in the liquid but nothing above $\mathrm{n}-\mathrm{C}_{19}$ is recovered from the soil. This poor recovery is related to the low vapor pressure of the large n-alkanes but also their affinity for soil organic matter, which can serve as an efficient absorbent.

Taking this into account, there are clear biotic effects on a HPD, most notably the nalkanes are rapidly degraded, eventually resulting in an unresolved alkane envelope comprised largely of branched alkanes. This creates the possibility that a petroleum distillate whose nalkanes had degraded could be misclassified as either an isoparaffinic or naphthenic-paraffinic liquid. Determining factors would be the extent of $n$-alkane degradation and the presence of cyclic alkanes. In this sample, the chromatogram takes on such an appearance after 7 days. Overall and in general, HPD samples degrade relatively rapidly (i.e., in less than 7 days), yielding a weak chromatographic profile that may present challenges for the determination of ILR in the sample.

There also appears to be some additional, albeit subtle, effects on the degraded HPD samples. The first is a systematic shift in the retention time of the unresolved envelope as degradation progresses (e.g., from $\sim 15 \mathrm{~min}$ at 0 days to $\sim 18 \mathrm{~min}$ after 21 days). This would typically be interpreted as a weathering effect, but as the samples were sealed in air tight cans, evaporative loss was not possible. As will be discussed below, there may be a relationship between the molecular weight and vapor pressure of a compound and the extent to which it is degraded by microbes.

A clearer trend is a greater relative loss of high boiling n-alkanes (e.g., n- $C_{15}, n-C_{17}$, and $\mathrm{n}-\mathrm{C}_{19}$ ) relative to low boiling $\mathrm{n}$-alkanes (e.g., $\mathrm{n}-\mathrm{C}_{11}$ and $\mathrm{n}-\mathrm{C}_{13}$ ). There is evidence that soil 
bacteria preferentially degrade alkanes that fall within a specific size range [4]. Alkanes that fall between 6 and 15 carbon atoms are neither too hydrophilic nor too hydrophobic, hence they can more readily diffuse through cell membranes [4]. However, our experiments show that the alkanes in HPDs can be well above this "goldilocks" zone - and it is these alkanes that appear to be degrading faster in this work. The biodegradation of SRN 020 exhibits similar changes, as found in the ILRC. Ultimately, additional experiments are warranted to ensure that this behavior can be reproduced in degradation experiments that proceed to a lesser degree.

The effects of weathering and microbial degradation on an aromatic liquid are shown in Figure 3. This aromatic liquid is comprised predominantly of alkyl benzenes with smaller contributions from naphthalene compounds. As the aromatic liquid is weathered, the trimethylbenzenes, which are the lowest boiling components in the sample, are the first to be affected followed by the higher boiling alkylbenzenes. As these components are lost, a relative increase in abundance of the higher boiling alkylbenzenes and naphthalenes is observed.

In contrast, as the liquid biodegrades, there is an overall degradation of all compounds at relatively similar rates. For example, although the relative amount of $\mathrm{C}_{3}$-alkylbenzenes is reduced over time, these compounds remain identifiable after 21 days on soil. Similarly, the $\mathrm{C}_{4^{-}}$ alkylbenzenes remain identifiable and their peak height ratios are largely unchanged. Two notable exceptions are naphthalene and 2-methylnaphthalene, which are rapidly diminished relative to the other aromatic compounds. This implies a potential selectivity of soil microbes for polyaromatic compounds such as the naphthalenes, however this requires further investigation. Interested readers can also examine SRN 284 in the ILRC.

Figure 4 compares the effects of weathering and microbial degradation on a miscellaneous liquid which contains a mixture of an aromatic and a heavy petroleum distillate. The changes in this liquid with weathering are solely based upon the boiling point of the various 
components. For example, at $25 \%$ weathered the $\mathrm{C}_{2}$-alkylbenzenes are lost, with some loss of the $\mathrm{C}_{3}$-alkylbenzenes and a slight increase in relative abundance of the alkane portion. Total loss of the $\mathrm{C}_{3}$-alkylbenzenes is observed at $50 \%$ weathered while the alkane portion remains largely unweathered. However, since the aromatics no longer remain, this liquid would be classified as an HPD. At $75 \%$ weathered, a significant decrease in $n-C_{11}$ and $n-C_{12}$ is observed and at $90 \%$ weathered, a clear shift in the chromatographic profile of the n-alkanes is observed.

A quite different trend is noted in the microbial degradation of this miscellaneous liquid. After exposure to the soil for 14 days, the $\mathrm{C}_{2}$-alkylbenzenes are completely lost. In addition, the n-alkanes also suffer from bacterial action and are largely consumed after 7 days. The $\mathrm{C}_{3^{-}}$ alkylbenzenes, being the most resistant to degradation, remain in the sample after 21 days.

The effects of weathering and microbial degradation on an isoparaffinic product are compared in Figure 5. As weathering increases, a loss of the lower boiling compounds is observed, while the relative abundance of the less volatile compounds increases. For example, the trimethylpentanes that are most abundant in the $0 \%$ weathered sample become less abundant while the trimethylhexanes, trimethylheptanes, and trimethyloctanes increase in abundance. However, in microbial degradation of this isoparaffinic product, the trimethylpentanes remain largely unaffected, while the trimethylhexanes, trimethylheptanes, and trimethyloctanes are almost completely degraded over the course of 21 days. While bacteria preferentially degrade n-alkanes and aromatics, when presented with a liquid comprised of only branched alkanes, they will degrade the long chain, lesser branched alkanes such as the trimethyloctanes found in the isoparaffinic liquid shown in Figure 5.

Figure 6 demonstrates the effects of weathering and microbial degradation of a normal alkane product. Although $\mathrm{n}-\mathrm{C}_{12}$ remains the most abundant alkane in all the weathered 
chromatograms, there is a significant change in the relative amounts of low boiling n-alkanes (i.e., $n-C_{10}$ and $n-C_{11}$ ) versus high boiling n-alkanes (i.e., $n-C_{13}$ and $n-C_{14}$ ).

In microbial degradation, the chromatograms are initially skewed towards lower boiling $\mathrm{n}$-alkanes, with $\mathrm{n}-\mathrm{C}_{11}$ being the most abundant. This is expected based upon the relatively low recovery of high boiling compounds from the soil matrix (as discussed above with HPDs). As the degradation process proceeds, $n-C_{10}$ and $n-C_{11}$ are lost at a slightly faster rate than $n-C_{12}$, resulting in a small change in the relative peak heights. The overall pattern, however, is preserved. It is important to note that a liquid composed solely of n-alkanes represents a much higher concentration of these compounds as opposed to other liquids with an n-alkane component. This allows this liquid to be readily identified, even after 21 days of degradation. In addition, this liquid consisted of a relatively narrow carbon number range, hence any preferences of the bacteria based upon molecular weight are not readily visible.

The naphthenic-paraffinic product shown in Figure 7 is not as significantly affected by weathering and microbial degradation. This liquid is comprised largely of branched alkanes and naphthenic compounds such as 2-methyl-trans-decalin. This liquid does contain a small contribution of n-alkanes, however. In weathering, the $\mathrm{n}-\mathrm{C}_{11}$ and 2-methyl-trans-decalin as well as the earlier eluting compounds are lost due to evaporation while the less volatile compounds, including $n-C_{12}$, show an increase in relative abundance.

In contrast, both $\mathrm{n}-\mathrm{C}_{11}$ and $\mathrm{n}-\mathrm{C}_{12}$ are the first to be degraded by the bacteria, while the relative abundance of 2-methyl-trans-decalin increases. Note that the prominent peak at $\sim 14$ min in the most degraded sample is safrole - a component of the root bark of the sassafras tree. This is an artifact from the potting soil substrate, which in some cases contained wood fragments. This anomaly was found in only one sample and it did not interfere with the identification of any other peaks in the chromatogram. 
Lastly, Figure 8 demonstrates the effects of weathering and microbial degradation on an oxygenated liquid. This liquid contains 2 oxygenated species, isopropanol (IPA) and butanone, which are the first two compounds to elute. This liquid also contains aromatic and aliphatic compounds. When this liquid was subjected to weathering, a loss of compounds based on boiling point was observed, where IPA and butanone decreased quickly followed by heptane and methylcylcohexane. At 95\% weathered, toluene and very small amounts of heptane and methylcylcohexane remained.

When this liquid was placed on a soil substrate, there was a dramatic and immediate decrease in recovery of IPA and butanone (0 days). This is attributed to adsorption and/or absorption of these small, water soluble components into the soil matrix. Thus, these compounds are not able to serve as visual references for the loss of the remaining compounds in the mixture. This essentially results in the degradation experiment being carried out on a three-component mixture (i.e., heptane, methylcyclohexane and toluene). Being an n-alkane, heptane is rapidly degraded in the soil. Similarly, toluene is a mono-substituted benzene that is degraded relatively easily, although it is still identifiable after 21 days due to its high initial concentration. Finally, methylcyclohexane is the most resistant to degradation and remains identifiable after 21 days.

\section{Conclusions}

Microbial degradation is based on the ability of bacteria to metabolize the compounds in ignitable liquids. In contrast, weathering results in the loss of all lower boiling compounds without bias, other than well-known changes in boiling point with molecular structure. In general, bacteria prefer to utilize n-alkanes and lesser substituted alkylbenzenes. Among the alkybenzenes, toluene is degraded first, followed by the $\mathrm{C}_{2}$-alkylbenzenes, then the $\mathrm{C}_{3^{-}}$ alkylbenzenes, and finally the $\mathrm{C}_{4}$-alkylbenzenes. Longer, lesser branched alkanes (e.g., 
trimethyloctanes) are also susceptible to microbial attack. All ignitable liquids examined suffered at least to some extent from microbial degradation, although gasoline, petroleum distillates, and oxygenates suffered the most, while the isoparaffinic and naphthenic paraffinic products were affected the least.

\section{ACKNOWLEDGEMENTS}

The authors would like to thank Mark Ahonen and Kathy Boone of the Microanalysis Unit of the Indiana State Police Laboratory for requesting research into the biodegradation of ignitable liquids. The authors would also like to thank the Ignitable Liquids Reference Collection Committee (ILRCC) in conjunction with the National Center for Forensic Science (NCFS) at the University of Central Florida (UCF) for feedback and guidance on the interpretation of the ILR chromatograms.

Additional Information and Reprint Requests:

John V. Goodpaster, Ph.D.

Associate Professor

402 North Blackford Street, LD 326

Indianapolis, IN 46202 
Table 1: Ignitable liquids used for this study, along with the Sample Reference Number (SRN) and ASTM classification (according to [13]).

\begin{tabular}{|c|c|c|}
\hline SRN* & Liquid & Class \\
\hline 1940 & Texaco Regular Unleaded Gasoline & Gasoline \\
\hline 1075 & Murphy USA Regular Gasoline & Gasoline \\
\hline 1011 & Shell Gasoline & Gasoline \\
\hline 1001 & Meijer E-85 Gasoline & Oxygenated \\
\hline 004 & Shellsol D43 & Medium Petroleum Distillate \\
\hline 005 & ShellSol A100 & Aromatic \\
\hline 008 & Shell Rubber Solvent 332 & Light Petroleum Distillate \\
\hline 010 & Cypar 9 & Miscellaneous (MPD+Aromatic) \\
\hline 012 & Shellsol Odorless Mineral Spirits & Medium Isoparaffinic \\
\hline 014 & STP Fuel Injector/Carburetor Cleaner & Heavy Petroleum Distillate \\
\hline 016 & STP Octane Booster & $\begin{array}{l}\text { Miscellaneous } \\
\text { (HPD + aromatic) }\end{array}$ \\
\hline 020 & Penske Fuel Injector/Carburetor Cleaner & Heavy Petroleum Distillate \\
\hline 021 & Mineral Spirits/Paint Thinner & Medium Petroleum Distillate \\
\hline 033 & Ronsonol Lighter Fluid & Light Petroleum Distillate \\
\hline 035 & Zippo Premium Lighter Fluid & Light Petroleum Distillate \\
\hline 039 & $\begin{array}{c}\text { Pennzoil Roadside Rescue Emergency Fuel } \\
\text { Additive }\end{array}$ & $\begin{array}{l}\text { Miscellaneous } \\
\text { (Isopar+Aromatic) }\end{array}$ \\
\hline 042 & Chevron Aviation Gasoline 100 LL & Miscellaneous (Isopar+toluene) \\
\hline 043 & Chevron Techron Concentrate & Heavy Petroleum Distillate \\
\hline 046 & Pro-Gard Fuel Injector PLUS Intake Valve Cleaner & Medium Petroleum Distillate \\
\hline 050 & Chevron Low Sulfur Diesel Fuel 2 & Heavy Petroleum Distillate \\
\hline 052 & Ortho Malathion 50 Plus Insect Spray Conc. & Aromatic \\
\hline
\end{tabular}




\begin{tabular}{|c|c|c|}
\hline 053 & Multipurpose Insect Killer & Naphthenic Paraffinic \\
\hline 059 & Adhesive Remover & Aromatic \\
\hline 064 & Whitaker Paint Thinner/Mineral Spirits & Medium Petroleum Distillate \\
\hline 069 & Whitaker \#51 Lacquer Thinner & Oxygenated \\
\hline 073 & Whitaker Ar-Sol 15 (Aromatic 150) & Aromatic \\
\hline 077 & Norpar 12 & Normal Alkane \\
\hline 087 & Isopar E & Light Isoparaffinic \\
\hline 089 & Isopar M & Medium Isoparaffinic \\
\hline 091 & E-Z Paint Thinner & Medium Petroleum Distillate \\
\hline 105 & Phillips 66 Unleaded Regular Gasoline & Gasoline \\
\hline 116 & Gasoline & Gasoline \\
\hline 119 & Isopar H & Medium Isoparaffinic \\
\hline 120 & Isopar C & Isoparaffinic \\
\hline 131 & Gum Turpentine & Miscellaneous \\
\hline 140 & Lamplight Farms Citronella Torch Fuel & Naphthenic Paraffinic \\
\hline 146 & Sunnyside Brush Cleaner & Miscellaneous (MPD+Aromatic) \\
\hline 149 & Sunnyside Denatured Alcohol Solvent & Oxygenated \\
\hline 176 & V \& O Lanterns Candle and Lamp Oil & Normal Alkane \\
\hline 182 & Prestone Heavy Duty Brake \& Parts Cleaner & $\begin{array}{c}\text { Miscellaneous } \\
\text { (LPD + aromatic) }\end{array}$ \\
\hline 185 & Pennzoil Marine Fuel System Cleaner & Naphthenic Paraffinic \\
\hline 192 & Northern Lights Lamp Fuel & Normal Alkane \\
\hline 201 & Summer Lights Citronella Outdoor Lamp Oil & Naphthenic Paraffinic \\
\hline 218 & PPG DT870 Reducer & Oxygenated \\
\hline 220 & PPG DT 895 Reducer & Oxygenated \\
\hline 231 & E-Z Water Wash Brush Cleaner & Oxygenated \\
\hline
\end{tabular}




\begin{tabular}{|c|c|c|}
\hline $\mathbf{2 3 6}$ & Aura Lamp Oil & Normal Alkane \\
\hline $\mathbf{2 5 8}$ & Chevron Regular Unleaded Gasoline & Gasoline \\
\hline $\mathbf{2 5 9}$ & Chevron Plus Unleaded Gasoline & Gasoline \\
\hline $\mathbf{2 8 4}$ & Exxon Aromatic 100 & Aromatic \\
\hline \multicolumn{3}{|c|}{ * Sample Reference Number from the ILRC. } \\
\hline
\end{tabular}




\section{REFERENCES}

1 Eric Stauffer, Julia A. Dolan, Newman R: Fire debris analysis. Burlington, Elsevier Inc, 2008.

2 Almirall JR, Furton KG: Characterization of background and pyrolysis products that may interfere with the forensic analysis of fire debris. J Anl Appl Pyrolysis 2004;71:51-67.

3 Stauffer E: Concept of pyrolysis for fire debris analysts. Sci Justice 2003;43:29-40.

4 Turner DA, Goodpaster JV: The effects of microbial degradation on ignitable liquids. Anal Bioanal Chem 2009;394:363-371.

5 Mann DC, Gresham WR: Microbial degradation of gasoline in soil. J Forensic Sci 1990;35:913-921.

6 Kirkbride KP, Yap SM, Andrews S, Pigou PE, Klass G, Dinan AC, Peddie FL: Microbial degradation of petroleum hydrocarbons: Implications for arson residue analysis. J Forensic Sci 1992;37:1585-1598.

7 Chalmers D, Yan SX, Cassista A, Hrynchuk R, Sandercock PMI: Degradation of gasoline, barbecue starter fluid, and diesel fuel by microbial action in soil. Can Soc Forens $\mathrm{J}$ 2001;34:49-62.

8 Turner DA, Goodpaster JV: The effect of microbial degradation on the chromatographic profiles of tiki torch fuel, lamp oil, and turpentine. J Forensic Sci 2011;56:984-987.

9 Turner DA, Goodpaster JV: Comparing the effects of weathering and microbial degradation on gasoline using principal components analysis. J Forensic Sci 2012;57:64-69.

10 Turner DA, Goodpaster JV: The effects of season and soil type on microbial degradation of gasoline residues from incendiary devices. Anal Bioanal Chem 2013;405:1593-1599.

11 Turner DA, Pichtel J, Rodenas Y, McKillip J, Goodpaster JV: Microbial degradation of gasoline in soil: Comparison by soil type. J Biorem Biodegrad 2014;5 (on-line).

12 Turner DA, Goodpaster JV: Preserving ignitable liquid residues on soil using triclosan as an anti-microbial agent. Forensic Sci Int 2014;239:86-91.

13 ASTM International: Astm E1618-11: Standard test method for ignitable liquid residues in extracts from fire debris samples by gas chromatography-mass spectrometry. West Conshohocken, PA, ASTM International, 2011. 


\section{FIGURE LEGENDS}

Figure 1: The effects of weathering versus microbial degradation of gasoline.

Figure 2: The effects of weathering versus microbial degradation of a heavy petroleum distillate.

Figure 3: The effects of weathering versus microbial degradation of an aromatic product.

Figure 4: The effects of weathering versus microbial degradation of a miscellaneous liquid.

Figure 5: The effects of weathering versus microbial degradation of an isoparaffinic product.

Figure 6: The effects of weathering versus microbial degradation of a normal alkane product.

Figure 7: The effects of weathering versus microbial degradation of a naphthenic-paraffinic product.

Figure 8: The effects of weathering versus microbial degradation of an oxygenated product. 